\title{
Spike overlap resolution of electrode and tetrode data from primary visual cortex Yasamin Mokri* and Shih-Cheng Yen
}

\author{
Address: Department of Electrical and Computer Engineering, National University of Singapore, Singapore 117576, Singapore \\ Email: Yasamin Mokri* - mokri@nus.edu.sg \\ * Corresponding author
}

from Seventeenth Annual Computational Neuroscience Meeting: CNS*2008

Portland, OR, USA. 19-24 July 2008

Published: II July 2008

BMC Neuroscience 2008, 9(SuppI I):P94 doi:I0.I I86/I47I-2202-9-SI-P94

This abstract is available from: http://www.biomedcentral.com/I47I-2202/9/SI/P94

(c) 2008 Mokri and Yen; licensee BioMed Central Ltd.

\section{Introduction}

The goal of an automated spike-sorting algorithm with the ability to resolve overlapping spike waveforms has long been a challenging problem. We have previously developed a method for resolving overlapping waveforms [1] but it required significant user input. We recently refined the method to reduce the amount of user input and have tested the new method on electrode and tetrode data.

\section{Methods}

32-point spike waveforms were extracted from the raw data on each channel using a multi-step procedure [1]. Automated clustering of the extracted waveforms was performed using the KlustaKwik software package [2]. The clusters with the largest number of waveforms were carefully inspected to verify that they consisted of highly similar waveforms and inter-spike intervals greater than $1 \mathrm{~ms}$. The remaining clusters were merged together to create the "overlap" cluster. The average waveform computed from these template clusters were then used to create all possible pairwise linearly superimposed waveforms. These superimposed waveforms were added to the overlap cluster and sent to KlustaKwik to be clustered automatically again. This resulted in the superimposed waveforms being clustered together with real overlapping waveforms in smaller clusters, while other waveforms, possibly the result of multi-unit activity or noise, were clustered together. Each cluster containing superimposed waveforms was then analyzed to find the superimposed waveform that was most highly correlated to each real overlapping waveform. The overlapping waveforms were then added to the appropriate pair of template clusters.

\section{Results}

The Fano Factor was used to investigate the performance of this method compared to manual sorting. In the electrode data (20 single units), recorded from the primary visual cortex of an awake behaving monkey, the Fano Factor was computed in $50 \mathrm{~ms}$ windows with 48 repetitions. In the tetrode data (18 single units), recorded from the primary visual cortex of an anesthetized cat, the Fano Factor was computed in $40 \mathrm{~ms}$ windows with 100 stimulus repetitions. We found the Fano Factors for automatic sorting to be equal or lower than those from manual sorting in $68.07+/-9.4 \%$ of the windows in the electrode data (n $=1613)$, and $68.01+/-9.5 \%$ of the windows in the tetrode data $(\mathrm{n}=9621)$. We also examined using the sumsquared-error (SSE) measure instead of the correlation coefficient in identifying the most appropriate superimposed waveform. Although the performance was lower using SSE $(59.7+/-17.9)$ for the tetrode data, it was not significantly different for the electrode data.

\section{Discussion}

Our new method appears to resolve overlapping waveforms as well as our previous, more labor intensive method with very few parameters. We are currently investigating extending this method to data recorded using silicon laminar probes. 


\section{Acknowledgements}

This work was supported by a grant from the Singapore Ministry of Education AcRF Tier I Fund (R263000355 I I2, R263000355 I33).

\section{References}

I. Shih-Cheng Y, Baker J, Gray CM: Heterogeneity in the responses of adjacent neurons to natural stimuli in cat striate cortex. J Neurophysiol 2007, 97: I326-I34I.

2. Harris KD, Henze DA, Csicsvari J, Hirase H, Buzsaki G: Accuracy of tetrode spike separation as determined by simultaneous intracellular and extracellular measurements. J Neurophysiol 2000, 84:40I-4I4

Publish with Biomed Central and every scientist can read your work free of charge

"BioMed Central will be the most significant development for disseminating the results of biomedical research in our lifetime. "

Sir Paul Nurse, Cancer Research UK

Your research papers will be:

- available free of charge to the entire biomedical community

- peer reviewed and published immediately upon acceptance

- cited in PubMed and archived on PubMed Central

- yours - you keep the copyright 